\title{
Endometrial tissue sampling using pipelle versus dilatation and curettage for the assessment of endometrium in patients of perimenopausal and post-menopausal age: a prospective study
}

\author{
Nina Navakumar ${ }^{1}$, Dhanya Dinesh ${ }^{2 *}$, P. K. Syamala Devi ${ }^{3}$
}

\begin{abstract}
${ }^{1}$ Department of High Risk Pregnancy and Fetal Medicine, Fernandez Hospital, Hyderabad, India ${ }^{2}$ Department of Gynecology and Oncology, Believers' Church Medical College and Hospital, Tiruvalla, Kerala, India ${ }^{3}$ Department of Obstetrics and Gynecology, KIMS Hospital, Trivandrum, Kerala, India
\end{abstract}

Received: 31 August 2018

Accepted: 06 September 2018

\section{*Correspondence:}

Dr. Dhanya Dinesh,

E-mail: dhanyadinesh13@gmail.com

Copyright: (c) the author(s), publisher and licensee Medip Academy. This is an open-access article distributed under the terms of the Creative Commons Attribution Non-Commercial License, which permits unrestricted non-commercial use, distribution, and reproduction in any medium, provided the original work is properly cited.

\section{ABSTRACT}

Background: The aim of this study is to compare the accuracy and adequacy of endometrial sampling using pipelle biopsy with dilatation and uterine curettage (D and C) and hysterectomy specimen in the assessment of endometrium in patients of perimenopausal and postmenopausal age.

Methods: One hundred fifty patients of perimenopausal and postmenopausal age who attended the Gynecology OPD of KIMS Hospital from June 2012 to May 2014 with complaints of abnormal uterine bleeding or who were found to have abnormally thickened endometrium by ultrasonography were included in the study.

Results: Adequate specimen could be obtained through pipelle biopsy in $86.7 \%$ of the patients, compared to $76 \%$ with adequate sample in case of D and C. Comparing histopathology reports between Pipelle and DandC specimens, the confidence interval was $92.7 \%, 95 \%$ lying in the range between $86.54 \%$ to $96.53 \%$. 68 of the 150 patients had undergone hysterectomy for various reasons. Comparing histopathology reports between Pipelle and hysterectomy specimens, the confidence interval was $94.2 \%$; $95 \%$ of study population lies within the C.I range of $84.05 \%-98.79 \%$ while accounting for the whole population, which shows that Pipelle endometrial sampling can be considered to be almost accurate as HPE by hysterectomy specimen. Comparing the difficulty of the procedure, Pipelle biopsy was found to be easier in perimenopausal patients when compared to post-menopausal patients and the difference was statistically significant. Mode of delivery did not seem to affect the ease of Pipelle endometrial sampling as per present observations.

Conclusions: Endometrial tissue sampling using Pipelle was found to be as reliable as D and C and hysterectomy specimen on histopathologic examination for the assessment of endometrium in perimenopausal and post-menopausal age group. Pipelle endometrial sampling was found to be yield adequate specimen when compared with D and C.

Keywords: Dilatation and curettage, Endometrial sampling, Pipelle biopsy

\section{INTRODUCTION}

Endometrial tissue sampling for histopathological examination is important in the assessment of endometrial pathology in the perimenopausal and postmenopausal age groups. Abnormal uterine bleeding is a major problem accounting for $33 \%$ of outpatient gynecological referrals. ${ }^{1}$ This proportion rises to $70 \%$ in the perimenopausal and postmenopausal years. ${ }^{2}$ Setzler and colleagues found that $18 \%$ of perimenopausal women had menorrhagia or metrorrhagia and one fifth of these were due to premalignant or malignant disease. ${ }^{3}$ Endometrial hyperplasia occurs in $5-10 \%$ of patients with post-menopausal bleeding. About $10 \%$ of patients with 
post-menopausal bleeding have endometrial cancer. In premenopausal women, AUB is diagnosed when there is a substantial change in frequency, duration, or amount of bleeding during or between periods. In postmenopausal women, any vaginal bleeding 1 year after cessation of menstruation is considered abnormal and requires proper evaluation. ${ }^{4}$ When a woman is found to have high risk factors for endometrial pathology, such as perimenopausal abnormal uterine bleeding, postmenopausal uterine bleeding, obesity or history of chronic anovulation; sampling of endometrium becomes mandatory.

To date, hysteroscopic biopsy and D and C is considered as the standard for endometrial sampling without its place in gynaecology being challenged. But in $60 \%$ of D and C, less than half of uterine cavity is curetted, with added risk of complications of general anesthesia, infection and perforation. ${ }^{5}$ This has led to the advent of simple methods for endometrial sampling. Various devices are in the market including the pipelle endometrial tissue sampler. Of the several office endometrial tissue sampling methods, the pipelle which is a disposable polypropylene sheath with an inner plunger has been found to be very comfortable and gave comparable histological findings with tissue obtained by $\mathrm{D}$ and $\mathrm{C}$ and hysterectomy specimen. ${ }^{5}$

Pipelle endometrial biopsy curette is easier to perform, cost effective and has better patient acceptability compared to dilatation and curettage (D and $\mathrm{C}$ ). However, there are still concerns regarding the adequacy of sample obtained, non-sampling of focal endometrial lesions and accuracy of histopathology report of tissues sampled. D and C is more commonly used even at tertiary care level. This study was done to determine accuracy of histopathologic findings of pipelle and adequacy of endometrium sampled by pipelle for histopathology in comparison to D and C.

\section{METHODS}

It was an observational diagnostic test study at KIMS Hospital (Kerala Institute of Medical Sciences), Trivandrum, a tertiary health care centre in South Kerala. Sample size was 150 patients. Duration of study was June 2012 to May 2014.

\section{Inclusion criteria}

- Perimenopausal women, 40 years or older, who present with abnormal uterine bleeding in whom structural pathology have been excluded.

- Patients with post-menopausal bleeding (one or more episodes).

- Postmenopausal patients with thickened endometrium (TVS-ET $\geq 4 \mathrm{~mm}$ ).

- Perimenopausal patients with thickened endometrium (TVS-ET $\geq 12 \mathrm{~mm}$ ).

\section{Exclusion criteria}

- Pregnancy, patients with lower genital tract infections, pelvic inflammatory diseases, coagulopathy, carcinoma cervix, fibroid uterus, congenital anomalies of uterus.

\section{Procedure}

A detailed clinical assessment of the patient was performed in the outpatient department including history, physical examination and base line investigations. A transvaginal sonography was performed before endometrial biopsy. The uterus was scanned in the sagittal and longitudinal projections with the use of 5.0to-7.5 MHz vaginal transducers. The thickest anteroposterior diameter of the endometrial stripe was then measured in the sagittal plane with digital calipers on the display. The endometrial thickness was then recorded in $\mathrm{mm}$. Diagnostic intervention endometrial sampling by pipelle device without anaesthesia followed by the diagnostic reference standard, endometrial sampling by $\mathrm{D}$ and $\mathrm{C}$ under anesthesia was then done after obtaining informed consent.

The patient was made to lie on her back on an examination table with her feet raised and supported by foot rests. Bimanual examination was done to assess the size and position of the uterus. The cervix was then visualized using a vaginal speculum and cleaned. A vulsellum was then applied to the anterior lip of the cervix to provide gentle traction whilst a sound was inserted through the cervical os. After assessing the position and size of the uterine cavity, the Pipelle was inserted through the cervical os and advanced until gentle resistance was felt. The pipelle device used for sampling was by Gynetics medical products, Belgium. It is a flexible thin device with inbuilt suction. The inner piston of the device is then withdrawn to create suction and the endometrial sample is obtained by moving the pipelle up and down within the uterine cavity by approximately $2-3$ centimeters.

The cannula was then rotated during removal and a strip of endometrium is peeled off and sucked into the syringe. This procedure was repeated at least four times and the device rotated 360 degrees to ensure adequate coverage of the area. The pipelle was then withdrawn from the cervical os and the endometrial sample expelled into a solution of formalin and labelled with a random number for transport to the laboratory. Following pipelle procedure, anesthesia was given and $\mathrm{D}$ and $\mathrm{C}$ procedure was done. Diagnostic curettage requires cervical dilatation to $>8 \mathrm{~mm}$.

After dilatation with Hegars dilators, a small sharp curette was introduced; systematic, thorough and gentle sampling of all parts of the uterine cavity was done and that sample was labelled with a random number. Both samples were sent to a histopathologist who was blinded 
as to the method of sample collection for histopathology assessment. Endometrial sampling procedure by pipelle was categorised by the doctor doing it as easy or not easy depending on the difficulty in traversing the cervix, the time taken for the procedure as a whole and discomfort it caused for the patient.

The histopathology report is noted, whether the sample contained endometrium, whether tissue was adequate, or not sufficient (scanty) for a histopathological diagnosis. The HPE of pipelle endometrial sampling was compared with HPE of D and C specimen to determine its accuracy, and adequacy of both specimens were also compared. Some patients had undergone hysterectomy due to various reasons and for them histopathological examination by endometrial tissue sampling was compared with HPE of hysterectomy also to determine its accuracy.

\section{Statistical analysis}

It is a descriptive study in which authors intended to assess the accuracy and adequacy of histopathological examination from pipelle and dilatation and curettage using 2 methods in which one was gold standard (hysterectomy specimen) and other was conventionally equivalent to gold standard (D and C). So, the accuracy was calculated and expressed as a percentage with $95 \%$ confidence interval.

Ninety-five \% confidence interval is a statement about the population prevalence of accuracy which says that if authors had studied the whole population, the population value of the accuracy will be contained in the $95 \%$ confidence interval and authors have also used percentages for describing the characteristics of the patient as well as the procedure. For assessing the association between two characteristics Chi square test or Fishers exact test were used whichever is appropriate.

\section{RESULTS}

The main patient and procedural characteristics are given in Table 1. 150 patients who underwent endometrial study over a period from June 2012 to May 2014 were included in the study. Majority of patients were between 46-50 years (28.7\%). $57.3 \%$ of patients were perimenopausal and $42.7 \%$ patients were postmenopausal. Only 2 patients $(1.3 \%)$ were nulliparous while $98.7 \%$ of the patients were primiparous and above (para-1, para-2, para-3 or more). $84 \%$ of the patients had at least 1 vaginal delivery where as $16 \%$ had only caesarean sections (did not have vaginal delivery). Only $10 \%$ patients had a history of prior cervical surgery like conisation cervix, amputation cervix, LEEP etc.

Among the perimenopausal patients in the study population, $38.4 \%$ of patients had endometrial thickness less than or equal to $10 \mathrm{~mm}, 37.2 \%$ patients had ET (TVS) between $11-15 \mathrm{~mm}$ and $24.4 \%$ patients had ET (TVS) more than or equal to $16 \mathrm{~mm}$. Among postmenopausal patients, $62.5 \%$ had ET (TVS) between 5-10 mm, 21.9\% patients had ET (TVS) more than or equal to $11 \mathrm{~mm}$ and $15.6 \%$ of patients had ET (TVS) less than or equal to 4 $\mathrm{mm}$. Adequate specimen could be obtained through pipelle endometrial tissue sampling in $86.7 \%$ of the patients, whereas only scanty/inadequate specimen was obtained for $13.3 \%$ of patients. $76 \%$ of patients in present study had adequate specimen from D and C. $24 \%$ of patients had only scanty specimen from $\mathrm{D}$ and $\mathrm{C}$.

Table 1: Patient characteristics and adequacy of specimen.

\begin{tabular}{|c|c|c|}
\hline & Frequency (n) & Percent \\
\hline \multicolumn{3}{|c|}{ 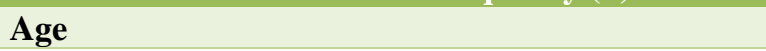 } \\
\hline $40-45 y$ & 33 & 22 \\
\hline $46-50 y$ & 43 & 28.7 \\
\hline $51-55 y$ & 28 & 18.7 \\
\hline $56-60 y$ & 18 & 12 \\
\hline$\geq 61 \mathrm{y}$ & 28 & 18.7 \\
\hline Total & 150 & 100.0 \\
\hline \multicolumn{3}{|l|}{ Menopausal status } \\
\hline Perimenopausal & 86 & 57.3 \\
\hline Postmenopausal & 64 & 42.7 \\
\hline Total & 150 & 100.0 \\
\hline \multicolumn{3}{|l|}{ Parity } \\
\hline Nulliparous & 2 & 1.3 \\
\hline Primipara and above & 148 & 98.7 \\
\hline Total & 150 & 100.0 \\
\hline \multicolumn{3}{|l|}{ Mode of delivery } \\
\hline No vaginal delivery & 24 & 16.0 \\
\hline At least one vaginal delivery & 126 & 84.0 \\
\hline Total & 150 & 100.0 \\
\hline \multicolumn{3}{|l|}{ Prior cervical surgeries } \\
\hline No & 135 & 90.0 \\
\hline Yes & 15 & 10.0 \\
\hline Total & 150 & 100.0 \\
\hline \multicolumn{3}{|l|}{ TVS-ET-perimenopausal } \\
\hline$\leq 10 \mathrm{~mm}$ & 33 & 38.4 \\
\hline $11-15 \mathrm{~mm}$ & 32 & 37.2 \\
\hline$\geq 16 \mathrm{~mm}$ & 21 & 24.4 \\
\hline Total & 86 & 100.0 \\
\hline \multicolumn{3}{|c|}{ TVS-ET-postmenopausal } \\
\hline$\leq 4 \mathrm{~mm}$ & 10 & 15.6 \\
\hline $5-10 \mathrm{~mm}$ & 40 & 62.5 \\
\hline$\geq 11 \mathrm{~mm}$ & 14 & 21.9 \\
\hline Total & 64 & 100.0 \\
\hline \multicolumn{3}{|c|}{ Adequacy of specimen-Pipelle } \\
\hline Inadequate specimen & 20 & 13.3 \\
\hline Adequate specimen & 130 & 86.7 \\
\hline \multicolumn{3}{|c|}{ Adequacy of specimen-D and C } \\
\hline Inadequate specimen & 35 & 24 \\
\hline Adequate specimen & 115 & 76 \\
\hline Total & 150 & 100.0 \\
\hline
\end{tabular}

Histopathology reports from pipelle, D and C and hysterectomy specimens are given in Table 2. 
Table 2: Histopathology.

\begin{tabular}{|lll|}
\hline Histopathological examination-pipelle & N & $\%$ \\
\hline Normal endometrium & 61 & 46.9 \\
\hline Endometrial polyp & 14 & 10.76 \\
\hline Disordered proliferative endometrium & 26 & 20 \\
\hline Endometrial hyperplasia & 22 & 16.9 \\
\hline Endometrial carcinoma & 7 & 5.38 \\
\hline Total & 130 & 100 \\
\hline Histopathological Examination-D and C & \\
\hline Normal endometrium & 49 & 42.6 \\
\hline Endometrial polyp & 14 & 12.17 \\
\hline Disordered proliferative endometrium & 21 & 14.0 \\
\hline Endometrial hyperplasia & 24 & 18.26 \\
\hline Endometrial carcinoma & 7 & 6.08 \\
\hline Total & 115 & 100 \\
\hline Histopathological examination-hysterectomy specimen \\
\hline Normal endometrium & 14 & 20.6 \\
\hline Endometrial polyp & 15 & 22.1 \\
\hline Disordered proliferative endometrium & 10 & 14.7 \\
\hline Endometrial hyperplasia & 22 & 32.35 \\
\hline Endometrial carcinoma & 7 & 10.29 \\
\hline Total & 68 & 100 \\
\hline & \multicolumn{2}{|c|}{} \\
\hline
\end{tabular}

Of the 130 patients with adequate specimen obtained by pipelle, $46.9 \%$ had normal endometrium which included atrophic endometrium, proliferative endometrium and secretory endometrium. $10.76 \%$ of patients had endometrial polyps, $20 \%$ had disordered proliferative endometrium and $16.9 \%$ had endometrial hyperplasia with or without atypia. $5.38 \%$ of patients in present study population had endometrial carcinoma according to HPE of pipelle endometrial sampling.

Of the 115 patients in whom adequate specimen was obtained by D and C, $42.6 \%$ of patients had normal endometrium. Endometrial hyperplasia was detected in $18.26 \%$ of patients and disordered proliferative endometrium in $14 \%$ of patients. Endometrial polyp was seen in $12.17 \%$ patients and $6.08 \%$ patients had Carcinoma endometrium.

Of the total 150 patients, hysterectomy was done only in 68 patients for various reasons. Of the 68 patients who underwent hysterectomy, $32.35 \%$ patients had endometrial hyperplasia, $22.1 \%$ patients had endometrial polyp, $14.7 \%$ had disordered proliferative endometrium, $10.29 \%$ patients had carcinoma endometrium and $20.6 \%$ patients had normal endometrium.

Table 3: Histopathological examination-pipelle* HPE-D and C comparison.

\begin{tabular}{|c|c|c|c|c|c|c|c|}
\hline \multicolumn{7}{|c|}{ Histopathological examination - D and C } & \multirow[t]{2}{*}{ Tota } \\
\hline & & $\begin{array}{l}\text { Normal } \\
\text { endometrium }\end{array}$ & $\begin{array}{l}\text { Endometrial } \\
\text { polyp }\end{array}$ & $\begin{array}{l}\text { Disordered } \\
\text { proliferative } \\
\text { endometrium }\end{array}$ & $\begin{array}{l}\text { Endometrial } \\
\text { hyperplasia }\end{array}$ & $\begin{array}{l}\text { Endometrial } \\
\text { carcinoma }\end{array}$ & \\
\hline \multirow{5}{*}{$\begin{array}{l}\text { Histopathological } \\
\text { examination- } \\
\text { pipelle }\end{array}$} & $\begin{array}{l}\text { Normal } \\
\text { endometrium }\end{array}$ & 44 & 1 & & 3 & & 48 \\
\hline & $\begin{array}{l}\text { Endometrial } \\
\text { polyp }\end{array}$ & 1 & 10 & & & & 11 \\
\hline & $\begin{array}{l}\text { Disordered } \\
\text { proliferative } \\
\text { endometrium }\end{array}$ & & & 21 & 1 & & 22 \\
\hline & $\begin{array}{l}\text { Endometrial } \\
\text { hyperplasia }\end{array}$ & 1 & 1 & & 19 & & 21 \\
\hline & $\begin{array}{l}\text { Endometrial } \\
\text { carcinoma }\end{array}$ & & & & & 7 & 7 \\
\hline Total & & 46 & 12 & 21 & 23 & 7 & 109 \\
\hline
\end{tabular}

One hundred nine patients had adequate samples on both pipelle and D and C. Of 48 patients whose HPER by pipelle endometrial sampling showed normal endometrium, 44 patients had normal endometrium by $\mathrm{D}$ and C,1 patient had endometrial polyp and 3 patients had endometrial hyperplasia. Of 11 patients who showed endometrial polyp on HPER by pipelle sampling, 10 patients had endometrial polyp HPER by D and C and 1 patient had normal endometrium. Of 22 patients who had disordered proliferative endometrium according to HPE by pipelle, 21 had disordered proliferative endometrium by $\mathrm{D}$ and $\mathrm{C}$ and 1 patient had endometrial hyperplasia. Of 21 patients who had endometrial hyperplasia by Pipelle, 19 cases had endometrial hyperplasia by D and C, 1 patient had normal endometrium and 1 patient had endometrial polyp. All 7 patients who had endometrial carcinoma by pipelle, had endometrial carcinoma by $\mathrm{D}$ and $\mathrm{C}$ also. On calculating confidence interval $(C I)=101 / 109=92.7 \%$, 95\% which lies within the range between $86.54 \%$ to $96.53 \%$ of the whole population. 
Table 4: Histopathological examination-pipelle * HPE-hysterectomy specimen.

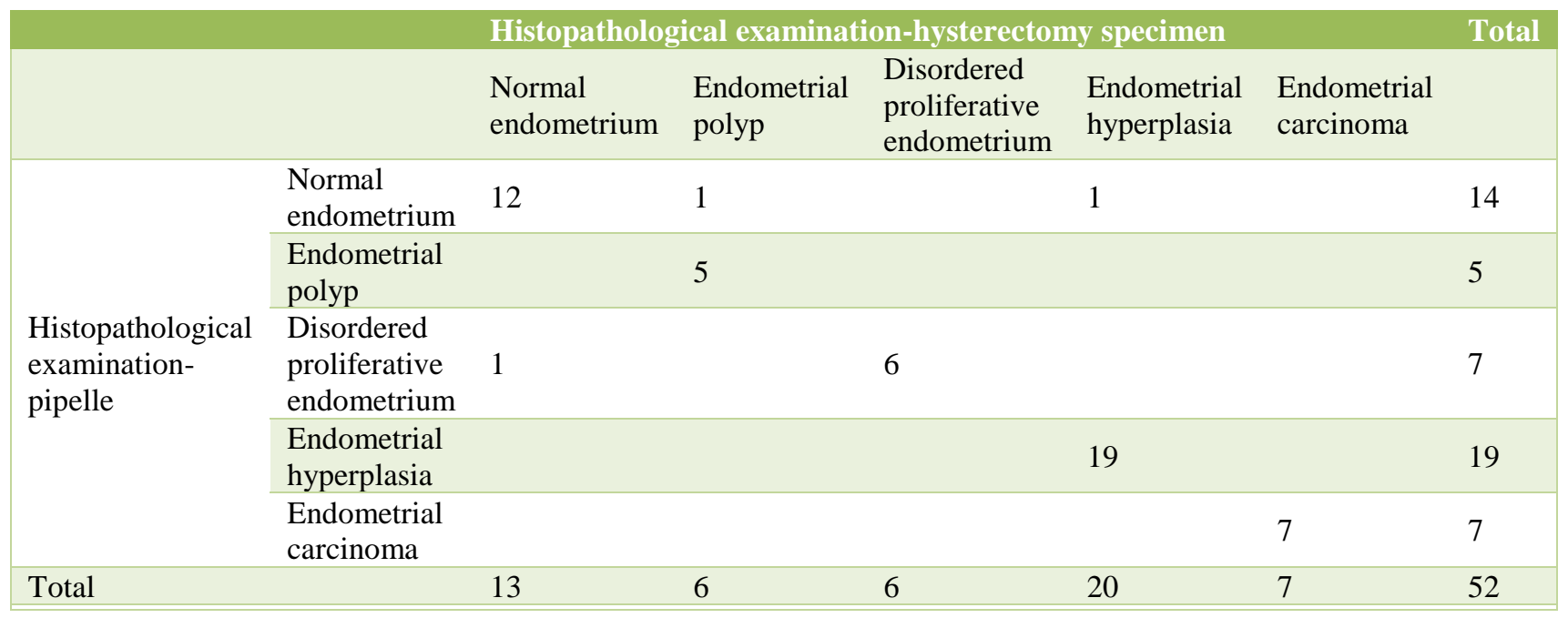

Out of 68 patients who had hysterectomy, 52 had adequate specimen on pipelle biopsy. Of the 14 patients who had normal endometrium by pipelle; 12 patients had normal endometrium according to hysterectomy specimen,1 case had endometrial polyp and 1 had endometrial hyperplasia. Of 5 cases who had endometrial polyp by pipelle; all 5 had endometrial polyp by hysterectomy specimen also. Of 7 cases who had disordered proliferative endometrium by pipelle; 6 had disordered proliferative endometrium on hysterectomy specimen and 1 case had normal endometrium. All 19 cases who had endometrial hyperplasia by pipelle; also had endometrial hyperplasia on hysterectomy specimen. All 7 cases who had endometrial carcinoma by pipelle had endometrial carcinoma on hysterectomy specimen also. CI for HPE by pipelle endometrial sampling was calculated in comparison with hysterectomy specimen (HPE) and was found to be $94.2 \%$; since 49 of 52 patients by HPE of pipelle endometrial sampling was found to have same HPE by hysterectomy specimen. This implies that confidence interval of $94.2 \%$; $95 \%$ of study population lies within the C.I range of $84.05 \%-98.79 \%$ while accounting for the whole population, which shows that pipelle endometrial sampling can be considered to be almost accurate as HPE by hysterectomy specimen.

Table 5: Menopausal status * difficulty of procedure-pipelle.

\begin{tabular}{|c|c|c|c|c|}
\hline & & \multicolumn{2}{|c|}{ Difficulty of procedure-pipelle } & \multirow{2}{*}{ Total } \\
\hline & & Easy & Not Easy & \\
\hline \multirow{2}{*}{ Menopausal status } & Perimenopausal & 63 & 23 & 86 \\
\hline & Post-menopausal & 35 & 29 & 64 \\
\hline Total & & 98 & 52 & 150 \\
\hline \multicolumn{5}{|l|}{ Chi-square tests } \\
\hline & Value & Asymp. Sig. (2-sided) & Exact Sig. (2-sided) & Exact Sig. (1-sided) \\
\hline Pearson chi-square & 5.586 & 0.018 & & \\
\hline Continuity correction & 4.796 & 0.029 & & \\
\hline Likelihood ratio & 5.568 & 0.018 & & \\
\hline Fisher's exact test & & & 0.024 & 0.014 \\
\hline Linear-by-linear association & 5.549 & 0.018 & & \\
\hline $\mathrm{N}$ of valid cases & 150 & & & \\
\hline
\end{tabular}

Among 86 perimenopausal patients Pipelle procedure was easy in 63 patients and difficult in 23 patients. Of 64 postmenopausal patients, Pipelle procedure was easy in
35 patients and difficult in 29 patients. By applying Chisquare test value was found to be 0.018 and the difference between 2 groups were found to be statistically significant. 
Table 6: Mode of delivery * difficulty of procedure-pipelle.

\begin{tabular}{|c|c|c|c|c|}
\hline & & Difficulty of procedu & re-pipelle & \\
\hline & & Easy & Not Easy & Iotal \\
\hline & No vaginal delivery & 17 & 7 & 24 \\
\hline Mode of delivery & $\begin{array}{l}\text { At least one vaginal } \\
\text { delivery }\end{array}$ & 81 & 45 & 126 \\
\hline Total & & 98 & 52 & 150 \\
\hline Chi-square tests & & & & \\
\hline & Value & Asymp. sig. (2-sided) & Exact sig. (2-sided) & Exact sig. (1-sided) \\
\hline Pearson chi-square & 0.382 & 0.537 & & \\
\hline Continuity correction & 0.147 & 0.701 & & \\
\hline Likelihood ratio & 0.390 & 0.532 & & \\
\hline Fisher's exact test & & & 0.643 & .356 \\
\hline Linear-by-linear association & 0.379 & 0.538 & & \\
\hline $\mathrm{N}$ of valid cases & 150 & & & \\
\hline
\end{tabular}

Among 24 patients who did not have even one vaginal delivery pipelle procedure was easy in 17 patients and it was difficult in 7 patients. Among 126 patients who had atleast one vaginal delivery, pipelle procedure was easy in 81 patients and it was difficult in 45 patients. By applying Chi-square test, value was found to be 0.537 and the difference between 2 groups were not statistically significant.

Table 7: Prior cervical surgery* difficulty of procedure-pipelle.

\begin{tabular}{|c|c|c|c|c|c|}
\hline & & & Difficulty of procedu & re-pipelle & \\
\hline & & & Easy & Not Easy & Total \\
\hline & No & & 94 & 41 & 135 \\
\hline Prior cervical surgery & Yes & & 4 & 11 & 15 \\
\hline Total & & & 98 & 52 & 150 \\
\hline Chi-square tests & & & & & \\
\hline & Value & $\mathrm{df}$ & Asymp. sig. (2-sided) & Exact sig. (2-sided) & Exact sig. (1-sided) \\
\hline Pearson chi-square & 11.002 & 1 & .001 & & \\
\hline Continuity correction & 9.187 & 1 & .002 & & \\
\hline Likelihood ratio & 10.438 & 1 & .001 & & \\
\hline Fisher's exact test & & & & .003 & .002 \\
\hline Linear-by-linear association & 10.929 & 1 & .001 & & \\
\hline $\mathrm{N}$ of valid cases & 150 & & & & \\
\hline
\end{tabular}

Among 135 patients who did not have a prior cervical surgery, pipelle procedure was easy in 94 patients and difficult in 41 patients. Among 15 patients who had prior cervical surgery, pipelle procedure was easy in 4 patients and difficult in 11 patients.

By applying Chi-square test value was found to be 0.001 and the difference between two groups were found to be statistically significant.

Among 86 patients who were perimenopausal, 80 had adequate specimen by pipelle and 6 patients had inadequate specimen. Among 64 perimenopausal patients, 50 had adequate specimen by pipelle and 14 had inadequate specimen. By applying the Chi-square test value was found to be 0.008 and the difference between the 2 groups were found to be statistically significant.

Among 86 perimenopausal patients, 68 had adequate specimen by $\mathrm{D}$ and $\mathrm{C}$ and 18 patients had only scanty specimen. Among 64 postmenopausal patients, 47 patients yielded adequate specimen by $\mathrm{D}$ and $\mathrm{C}$ and 17 patients had only inadequate specimen. By applying Chisquare test value was found to be 0.526 and difference between 2 groups were not statistically significant. 
Table 8: Menopausal status * adequacy of specimen-pipelle.

\begin{tabular}{|c|c|c|c|c|}
\hline & & \multicolumn{2}{|c|}{ Adequacy of specimen-pipelle } & \multirow{2}{*}{ Total } \\
\hline & & Inadequate specimen & Adequate specimen & \\
\hline \multirow{2}{*}{ Menopausal status } & Perimenopausal & 6 & 80 & 86 \\
\hline & Post-menopausal & 14 & 50 & 64 \\
\hline Total & & 20 & 130 & 150 \\
\hline \multicolumn{5}{|l|}{ Chi-square tests } \\
\hline & Value & Asymp. Sig. (2-sided) & Exact Sig. (2-sided) & Exact Sig. (1-sided) \\
\hline Pearson chi-square & 7.048 & .008 & & \\
\hline Continuity correction & 5.818 & .016 & & \\
\hline Likelihood ratio & 7.039 & .008 & & \\
\hline Fisher's exact test & & & .014 & .008 \\
\hline Linear-by-linear association & 7.001 & .008 & & \\
\hline $\mathrm{N}$ of valid cases & 150 & & & \\
\hline
\end{tabular}

Table 9: Menopausal status * adequacy of specimen-D and C.

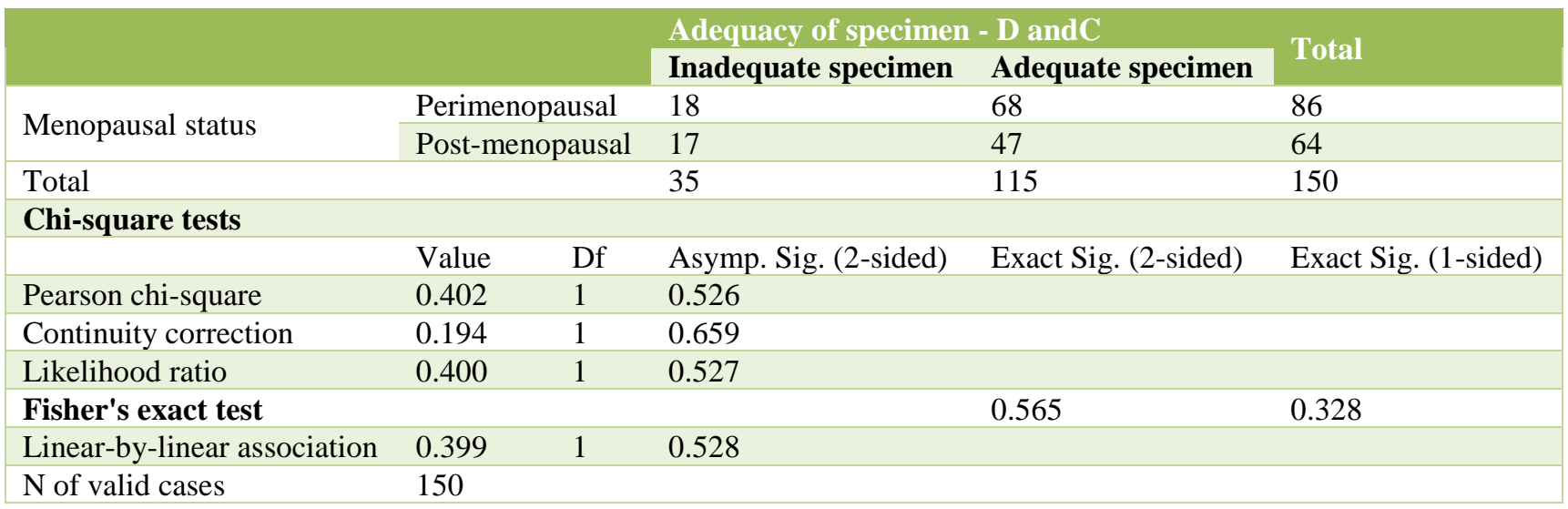

\section{DISCUSSION}

This study was carried out to determine the accuracy of pipelle endometrial tissue sampling in the assessment of endometrium by comparing it with histopathology of dilatation and curettage and hysterectomy specimens, and also to compare the adequacy of specimen obtained by pipelle endometrial sampling with $\mathrm{D}$ and $\mathrm{C}$ specimen. The difficulty of pipelle procedure and factors associated with it were also studied.

Comparing histopathology reports of pipelle and D and C specimens, CI for HPE by pipelle endometrial sampling was calculated in comparison with D and C (HPE) and was found to be $92.7 \%$ since 101 patients of 109 patients by HPE of pipelle endometrial sampling was found to have same HPE according to $\mathrm{D}$ and $\mathrm{C}$ specimen. This implies that confidence interval of $92.7 \%$; $95 \%$ of study population lies within the C.I range of $86.54 \%-96.53 \%$ while accounting for the whole population, which shows that pipelle endometrial sampling can be considered to be almost accurate as HPE by D and $\mathrm{C}$ specimen. Thus, pipelle endometrial sampling can be used instead of $\mathrm{D}$ and $\mathrm{C}$ as an OPD procedure for diagnosing endometrial pathology. The pipelle device picked up all cases of endometrial carcinoma. Thus, predictive value of pipelle for diagnosing endometrial carcinoma is $100 \%$ compared to $\mathrm{D}$ and $\mathrm{C}$ in present study. No complications were noted in both $\mathrm{D}$ and $\mathrm{C}$ and pipelle sampling.

CI for HPE by pipelle endometrial sampling was calculated in comparison with hysterectomy specimen (HPE) and was found to be $94.2 \%$ since 49 of 52 patients by HPE of pipelle endometrial sampling was found to have same HPE by hysterectomy specimen. This implies that confidence interval of $94.2 \%$; $95 \%$ of study population lies within the C.I range of $84.05 \%-98.79 \%$ while accounting for the whole population, which shows that pipelle endometrial sampling can be considered to be almost accurate as HPE by hysterectomy specimen.

Correlating menopausal status of the patients with difficulty of procedure, the difference was statistically significant. Pipelle endometrial sampling was found to be easier in perimenopausal patients when compared to postmenopausal patients in present study.

Though it may be expected that the procedure would be tough in patients who did not have a previous vaginal delivery, mode of delivery did not seem to affect the ease 
of pipelle endometrial sampling as per present observations. Previous studies by Williams et al reported that nulliparity was significantly associated with insertion failure for pipelle. ${ }^{6}$ However, another study by Bakour et al reported that there was no association between adequate sample and parity using multivariate regression analysis model. ${ }^{7}$

In present study authors observed that pipelle procedure was difficult in patients who had prior cervical surgeries and the difference between the 2 groups were statistically significant.

$\mathrm{D}$ and $\mathrm{C}$ and pipelle had comparable results with respects to adequacy of sample as per present observations. In present study $86.7 \%$ patients yielded adequate specimen for histopathological examination by pipelle endometrial sampling; in $13.3 \%$ patients adequate specimen could not be obtained through pipelle endometrial sampling. $76 \%$ patients yielded adequate specimen for HPE by D and $\mathrm{C}$; in $24 \%$ patients adequate specimen could not be obtained through D and C.

Correlating menopausal status with adequacy of specimen in pipelle endometrial sampling, difference between 2 groups were statistically significant with a $p$ value of 0.008 . Authors observed in present study that pipelle endometrial sampling could be more easily done in perimenopausal patients. Correlating menopausal status with adequacy of specimen obtained through D and $\mathrm{C}$, the difference between 2 groups were not statistically significant with a $\mathrm{p}$ value of 0.526 .

In a study comparing pipelle with $\mathrm{D}$ and $\mathrm{C}$, Fakhar $\mathrm{S}$ et al reports that an adequate sample was obtained in $98 \%$ of cases by pipelle and in $100 \%$ of cases by $\mathrm{D}$ and $\mathrm{C} .{ }^{8}$ Pipelle had a sensitivity, specificity, positive predictive value and negative predictive value of $100 \%$ for diagnosing endometrial carcinoma, hyperplasia and secretory endometrium.

Studies have reported the success of pipelle in obtaining an adequate sample ranging from $67 \%$ to $98 \% .^{9-13}$ In present study comparing pipelle with $\mathrm{D}$ and $\mathrm{C}$ in adequacy of specimen obtained, pipelle procedure yielded specimen in $86.7 \%$ of patients and D and C procedure in $76.7 \%$ of patients.

In a study by Stovall et al to determine the reliability of pipelle in the diagnosis of endometrial carcinoma and to compare the histopathology reports with the subsequent hysterectomy specimen, sensitivity of pipelle was found to be $97.5 \% .{ }^{14}$ Pipelle biopsy correlated with the $\mathrm{D}$ and $\mathrm{C}$ histology in $83.3 \%$. This study demonstrated pipelle to be an accurate device for sampling in endometrial carcinoma.

In the study by Choudary $\mathrm{A}$ et al the study revealed sample adequacy of $98 \% .^{2}$ The pipelle procedure proved to be simple, acceptable, accurate, and cost effective.
Studies by Shazia et al have proved pipelle to be cost effective. The average cost of a pipelle sampling is Rs.850 (Rs.450 for pipelle device and Rs.500 for histopathological examination) compared to Rs.10000 of $\mathrm{D}$ and $\mathrm{C}$ which includes procedure, anesthesia, surgery and inpatient charges. ${ }^{8}$ Pipelle is certainly cost effective than D and C. Feldman et al tried to identify an optimal evaluation strategy for patients of various ages and risks for endometrial cancer and for complex hyperplasia who presented with first episode of postmenopausal bleeding. ${ }^{9}$ Office biopsy was the most cost-effective initial strategy.

\section{CONCLUSION}

Endometrial tissue sampling by using pipelle comparing with dilatation and curettage and hysterectomy specimen in assessment of endometrium by histopathological examination in patients of peri-menopausal and postmenopausal age was found to be as reliable as the other two methods. Pipelle endometrial tissue sampling was found to yield adequate specimen when compared with dilatation and curettage for histopathological examination.

Funding: No funding sources

Conflict of interest: None declared

Ethical approval: The study was approved by the Institutional Ethics Committee

\section{REFERENCES}

1. Yasmin F, Farrukh R, Kamal F. Efficacy of pipelle as a tool for endometrial biopsy. Biomedica. 2007;23:116-9.

2. Choudry A, Javaid M. Clinical usefulness of Pipelle endometrial sampling. Pak Armed Forces Med J. 2005;55:122-5.

3. Seltzer V, Benjamin F, Deutsch S. Perimenopausal bleeding patterns and pathologic findings. J Am Med Women's Association.1990;45:132-4.

4. Dijkhuizen FP, Mol BW, Brölmann HA, Heintz AP. The accuracy of endometrial sampling in the diagnosis of patients with endometrial carcinoma and hyperplasia: a meta-analysis. Cancer. 2000;89(8):1765-72.

5. Seamark CJ. The demise of the D\&C. J Royal Soc Med. 1998;91(2):76-9.

6. Williams AR, Brechin S, Porter AJ, Warner P, Critchley HO. Factors affecting adequacy of Pipelle and Tao Brush endometrial sampling. BJOG: An Int J Obstet Gynaecol. 2008;115(8):1028-36.

7. Bakour SH, Khan KS, Gupta JK. Controlled analysis of factors associated with insufficient sample on outpatient endometrial biopsy. Br J Obstet Gynaecol. 2000;107:1312-4.

8. Fakhar S, Saeed G, Khan A, Alam A. Validity of pipelle endometrial sampling in patients with abnormal uterine bleeding. Annals Saudi Med. 2008;28(3):188. 
9. Feldman S, Berkowitz RS, Tosteson ANA. Costeffectiveness of strategies to evaluate postmenopausal bleeding. Obstet Gynecol. 1993;81:968-75.

10. Ben-Baruch G, Seidman DS, Schiff E, Moran O, Menczer J. Outpatient endometrial sampling with the Pipelle curette. Gynecol Obstet Investig. 1994;37(4):260-2.

11. Epstein E, Valentin L. Intraobserver and interobserver reproducibility of ultrasound measurements of endometrial thickness in postmenopausal women. Ultrasound Obstet Gynecol 2002;20:486-91.

12. Machado F, Moreno J, Carazo M, Leon J, Fiol G, Serna R. Accuracy of endometrial biopsy with the Cornier pipelle for diagnosis of endometrial cancer and atypical hyperplasia. Europ J Gynaecol Oncol. 2003;24(3-4):279-81.
13. Gordon SJ, Westgate. J. The incidence and management of failed pipelle sampling in a general outpatient clinic. Aust Nzj Obstet Gynecol. 1999;39:115-8.

14. Stoval TG, Ling FW, Morgan PL. A prospective, randomized comparison of the pipelle endometrial sampling device with the novak curette. Am J Obstet Gynecol. 1991;165:1287-90.

Cite this article as: Navakumar N, Dinesh D, Devi PKS. Endometrial tissue sampling using pipelle versus dilatation and curettage for the assessment of endometrium in patients of perimenopausal and postmenopausal age: a prospective study. Int J Reprod Contracept Obstet Gynecol 2018;7:3951-9. 